\title{
Association between serum levels of hepcidin and ferritin in patients with thalassemia major and intermedia, the role of iron chelator
}

\author{
Seyed Kamal Eshagh Hossaini ${ }^{1}$ - Mohammad reza Haeri ${ }^{2}$
}

Received: 15 April 2019 / Accepted: 4 July 2019 /Published online: 11 July 2019

(C) Springer-Verlag GmbH Germany, part of Springer Nature 2019

\begin{abstract}
Patients with beta-thalassemia suffer from iron overload, and hepcidin, as the main regulator of iron hemostasis, can indicate iron overload better than serum ferritin, but changes in serum hepcidin levels are affected by the type of thalassemia (major or intermediate) and by type of treatments. The present study aimed to determine the correlation between serum levels of hepcidin and ferritin in patients with thalassemia major and intermedia under chelation therapy. This cohort study investigated 143 patients with thalassemia (122 patients with thalassemia major and 21 patients with and thalassemia intermedia) who referred to Thalassemia Center of Qom University of Medical Sciences, Qom, Iran. The serum level of ferritin was measured twice in all patients: in the beginning and after taking iron chelator by ECL method. Hepcidin was assayed at the end of the study by ELISA methods. Demographic data and clinical history of the patients (type of disease, type of drugs used, and blood transfusion history) were completely recorded. The mean serum level of hepcidin in the TM group $(2249.62 \pm 1547.37 \mathrm{ng} / \mathrm{ml})$ was greater than the TI group $(1482.43 \pm 1314.26 \mathrm{ng} / \mathrm{ml})(p=0.007)$. However, there was no meaningful difference in serum ferritin level between the two groups ( $2997.74 \pm 2545.66$ vs. $2670.62 \pm 2670.04 \mathrm{ng} / \mathrm{ml}, p>0.05$ ). Serum ferritin and hepcidin levels were not correlated both in TM or TI patients $(p>0.05)$. However, evaluating the trend of changes in serum levels of ferritin with hepcidin showed a significant association. High serum levels of ferritin indicated high iron overload in both groups, TM and TI, which decreased after treatment with chelators. The higher hepcidin levels in TM patients in comparison to TI patients could reflect the higher iron overload in these patients. However, further cellular studies are needed to evaluate the accuracy of these tests in the assessment of iron overload.
\end{abstract}

Keywords Hepcidin $\cdot$ Ferritin $\cdot$ Beta-thalassemia

\section{Introduction}

Thalassemia refers to a group of hereditary single gene disorders caused by deficient or absent synthesis of hemoglobin chains; mutation in the $\beta$-globin chain results in $\beta$ thalassemia [1], which is considered the most common type in Mediterranean, African, and Asian ethnicities [2]. Betathalassemia is a public health problem with an estimated increasing prevalence [3]. Despite the substantial decrease in the incidence of thalassemia since the implementation of the

Mohammad reza Haeri

haeri.mr@gmail.com

1 Departmennt of Pediatrics, Faculty of Medicine, Qom University of Medical Sciences, Qom, Iran

2 Depatment of Clinical Biochemistry, Faculty of Medicine, Qom University of Medical Sciences, Qom, Iran
National Thalassemia prevention program $[4,5]$, the disease burden is still high in Iran and other developing countries [6].

According to disease severity, thalassemia is classified into major, intermedia, and minor (trait): patients with thalassemia major (TM) are transfusion dependent and require more than eight red blood cell (RBC) transfusions per year, while those with thalassemia intermedia (TI) are non-transfusion dependent and require no or infrequent transfusions [7]. Although blood transfusion is the primary treatment of these patients, it is associated with several adverse effects, including iron overload, if untreated results in tissue and organ damages and increases mortality [8]. Several iron chelators have been suggested to prevent iron overload [9]. Furthermore, iron overload is observed, independent of blood transfusion, in TI patients [10], hypothesized to be due to the increased gastrointestinal iron absorption caused by suppression of hepcidin [11].

Hepcidin, a hormone produced in the liver, regulates iron hemostasis in the body based on hypoxia, anemia, and iron stores and controls the serum concentration and tissue 
distribution of iron [12]. Ineffective erythropoiesis (IE) in $\beta$ thalassemia alters the secretion of hepcidin [13]. Several studies have focused on serum, urinary, and liver concentrations of hepcidin in patients with $\beta$-thalassemia $[14,15]$. Due to the differences in iron distribution according to the cell or tissue type [16] and variations in ferritin levels, by inflammation and infection, researchers have been searching for a valid tool indicating iron overload and its tissue distribution in patients with $\beta$-thalassemia [17] and hepcidin can be that solution. Accordingly, the present study aimed to determine the correlation between serum levels of hepcidin and ferritin in patients with TM and TI after treatment with iron chelators.

\section{Patients and methods}

\section{Study design}

In this cohort study, 143 patients with thalassemia who referred to Thalassemia Center of Qom University of Medical Sciences (between 2018 and 2018) were selected (122 with TM and 21with TI) using convenience sampling.

Inclusion criteria were based on complete blood count (CBC) and hemoglobin electrophoresis, and patients $>2$ years old who were under regular examination and treatment were included in the study. Patients requiring regular blood transfusion and chelation therapy $(30-40 \mathrm{mg} / \mathrm{Kg} /$ day tablet or 40
$50 \mathrm{mg} / \mathrm{Kg} /$ day, injection form, Novartis Switzerland) were sorted to TM group, and patients who did not require regular blood transfusion and received mainly chelator were sorted to TI group.

Exclusion criteria, for both groups, $\mathrm{C}$ reactive protein (CRP) positive patients and patients with a history of infection and fever (during the past 3 months), surgery, cardiovascular disease, any clinical sign of liver disease, abnormal liver function tests (evaluated by ALT and AST measurement), or nephrotic syndrome were excluded from the study (Fig. 1). Furthermore, liver function tests were performed for all the patients every 2 months.

All the necessary information about the study were given to the patients and they were included in the study after signing the informed consent form. Blood transfusions were performed every 2-3 weeks so that hemoglobin levels were stable within a 9-9.5 range. Demographic data, the type of drugs used, and blood transfusion was recorded. A blood sample was taken from each patient ( $5 \mathrm{ml}$ venous blood sample) in the early morning after overnight fasting with an exact fasting time before and after treatment with iron chelators. Furthermore, blood sampling was performed right before blood transfusion for patients who needed a blood transfusion. The samples were processed immediately and sera were removed and stored at $-20{ }^{\circ} \mathrm{C}$ until assay. Serum levels of ferritin and hepcidin were measured by ECL (Roch diagnostics, Germany) and ELISA methods (DRG, Germany) respectively.
Fig. 1 Instructions in step-bystep selecting the thalassemia patients based on the defined exclusion and inclusion criteria

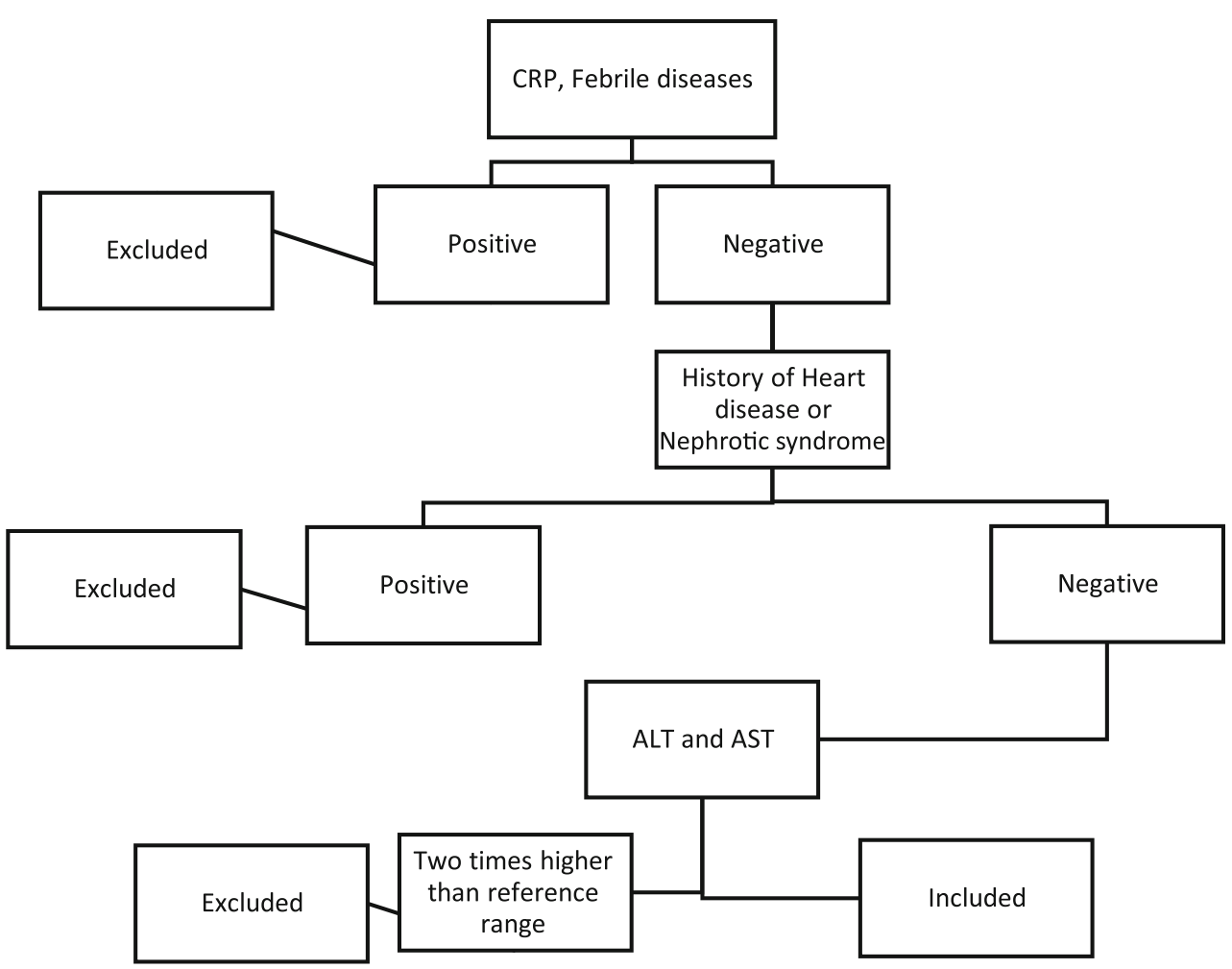


Table 1 Comparison of mean, median, and interquartile range of ferritin and hepcidin between patients with thalassemia major and intermedia

\begin{tabular}{|c|c|c|c|c|c|c|c|}
\hline Variable & Group & Mean & Standard deviation & Median & Q1 & Q3 & $p$ value \\
\hline Hepcidin, ng/ml & $\begin{array}{l}\text { Thalassemia major } \\
\text { Thalassemia intermedia }\end{array}$ & $\begin{array}{l}2289.62 \\
1482.43\end{array}$ & $\begin{array}{l}1547.37 \\
1314.26\end{array}$ & $\begin{array}{c}1796.5 \\
922\end{array}$ & $\begin{array}{l}982.25 \\
687.5\end{array}$ & $\begin{array}{l}3584 \\
2085\end{array}$ & 0.007 \\
\hline Ferritin, ng/ml & $\begin{array}{l}\text { Thalassemia major } \\
\text { Thalassemia intermedia }\end{array}$ & $\begin{array}{l}2997.74 \\
2670.62\end{array}$ & $\begin{array}{l}2545.66 \\
2670.04\end{array}$ & $\begin{array}{l}2307 \\
1461\end{array}$ & $\begin{array}{r}1092.7 \\
605.5\end{array}$ & $\begin{array}{l}4144.7 \\
3910\end{array}$ & 0.337 \\
\hline
\end{tabular}

\section{Statistical analysis}

Normal distribution of data was tested using the KolmogorovSmirnov and Shapiro Wilk test. Results showed that serum levels of hepcidin and ferritin did not have a normal distribution. Thus, groups were compared using the Mann-Whitney $U$ Test, and correlations were tested by Spearman's correlation coefficient. Data were analyzed using SPSS (Version 18.0, released 2009, Chicago: SPSS Inc.) and expressed as mean \pm SD or median and interquartile range (IQR) if variables were not normally distributed. $p$ values $\leq 0.05$ were considered significant.

\section{Results}

The total number of patients included in the study were 143: 122 patients with TM (85.3\%) and 21 patients with TI. There were no significant differences in age between TM (21.57 \pm $10.28)$ and TI group $(22.44 \pm 9.32)$. In the TM group, $49.2 \%$ were male and $50.8 \%$ were female and in TI group, $57.1 \%$ were male and $42.9 \%$ were female.

Median serum level of hepcidin in all patients was $1675 \mathrm{ng} / \mathrm{ml}$ (Q1:925-Q3:3184). The mean and median serum level of hepcidin were significantly higher in the TM group

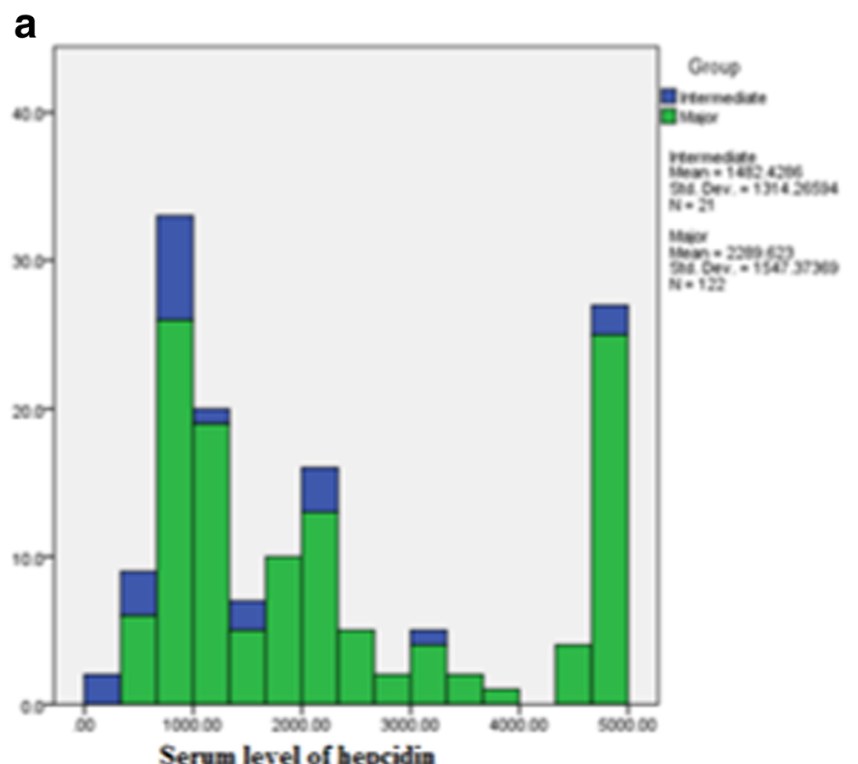

than the TI group $(p=0.007)$ (Table 1). This difference remained significant after controlling the effect of independent variables (age and sex) $(p=0.025)$. Figure 2 shows the distribution of serum levels of hepcidin in the two groups and comparing the median levels between the groups.

Median serum level of ferritin in all patients was $2251 \mathrm{ng} / \mathrm{ml}(\mathrm{Q} 1: 1011-\mathrm{Q} 3: 4135)$. Mean $\pm \mathrm{SD}$ of serum ferritin level was $2997.74 \pm 2545.66 \mathrm{ng} / \mathrm{ml}$ in the TM group and $2670.62 \pm 2670.04 \mathrm{ng} / \mathrm{ml}$ in the TI group and there was no significant difference between the groups in this regard ( $p=$ 0.337), which remained non-significant even after controlling the effect of independent variables (age and sex). The distribution of serum levels of ferritin in the two groups and median levels of ferritin in each group are shown in Fig. 3.

Comparing the serum levels of ferritin at the beginning and the end of the study showed a significant decrease of ferritin levels from $2307 \mathrm{ng} / \mathrm{ml}$ before treatment to $1119 \mathrm{ng} / \mathrm{ml}$ after treatment $(p<0.001$.

There was no significant association between serum levels of hepcidin and ferritin in the TM group $(p=0.51, r=-0.06)$ or TI group ( $p=0.071, r=0.402$, Spearman's correlation). Evaluating the trend of changes in serum levels of ferritin with hepcidin showed a significant association $(r=0.347$, $p<0.001$, Spearman's correlation) (Fig. 4).

\section{b}

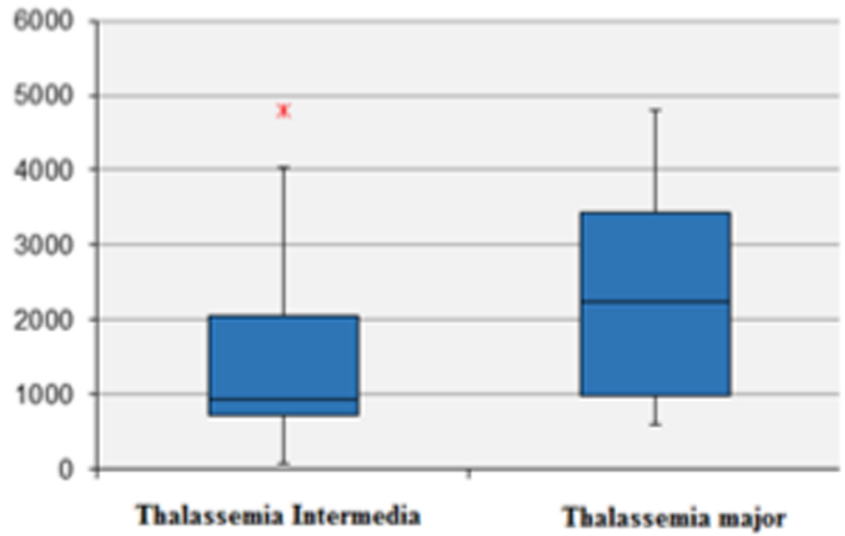

Fig. 2 a The distribution of serum level of hepcidin in patients with thalassemia major and intermedia and $\mathbf{b}$ comparing the median values of serum level of hepcidin between patients with thalassemia major and intermedia 


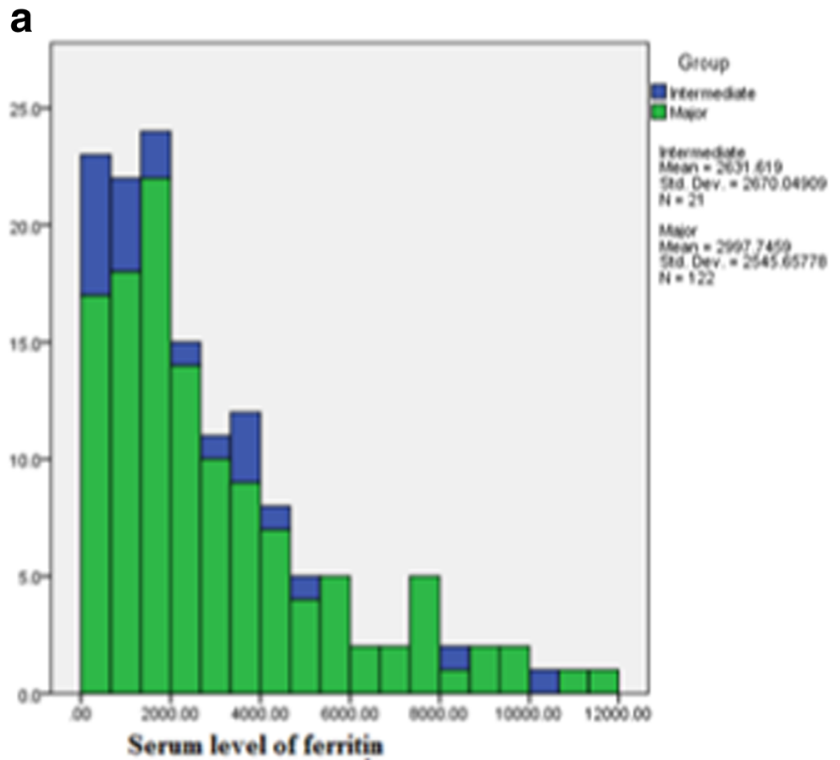

b

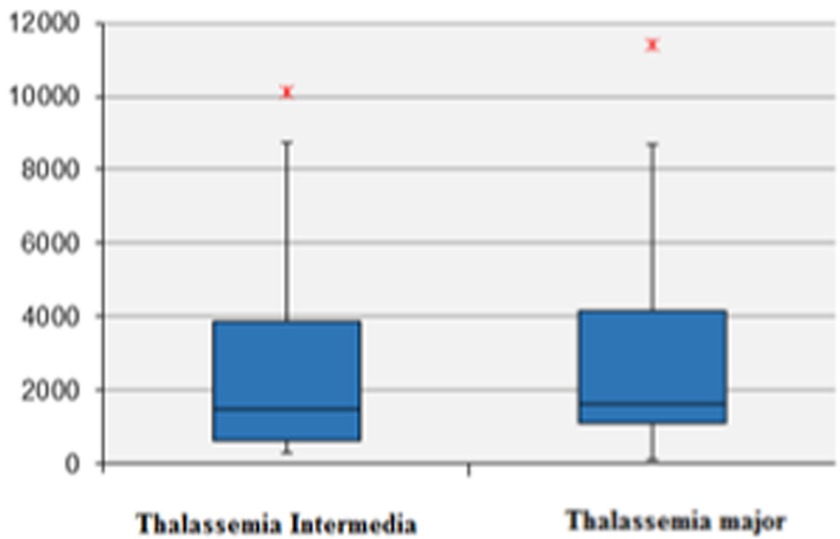

Fig. 3 a The distribution of serum level of ferritin in patients with thalassemia major and intermedia and $\mathbf{b}$ comparing the median values of serum level of ferritin between patients with thalassemia major and intermedia

\section{Discussion}

The results of the present study indicated that serum levels of ferritin were rigorously high, both in the TM and TI groups (median 2307 and 1461, respectively), which indicates that iron overload is an important issue in TM and TI patients. Iron overload may be a result of blood transfusion [8] and ineffective and extramedullary erythropoiesis [18]. In the present study, the significant decrease in ferritin levels after treatment showed the efficacy of the therapy. Moreover, the results of this study revealed that patients with TI also suffer from iron overload, which has to be managed appropriately. Accumulation of iron in the absence of blood transfusions may result from inappropriate suppression of hepcidin by an erythropoietic mechanism [19, 20].
The present study on patients with $\beta$-thalassemia showed high serum level of hepcidin (median $1675 \mathrm{ng} / \mathrm{ml}$ ), which was not associated with ferritin levels. Assessment of hepcidin as the most appropriate tool for evaluating iron overload is of great importance, as the liver is the main site of both iron and hepcidin [19].

In this study, the serum level of hepcidin was high in both groups and significantly higher in patients with TM than those with TI, which indicates the high iron overload in the studied patients. However, despite the fact that ferritin in the TM group was higher in comparison to the TI group, this difference was not significant. Moreover, there was also no significant association between serum level of ferritin and hepcidin. A similar result was obtained by Haghpanah and colleagues, in their study, serum level of ferritin was also higher in the TM
Fig. 4 The association between changes in serum levels of ferritin and hepcidin in patients with thalassemia major

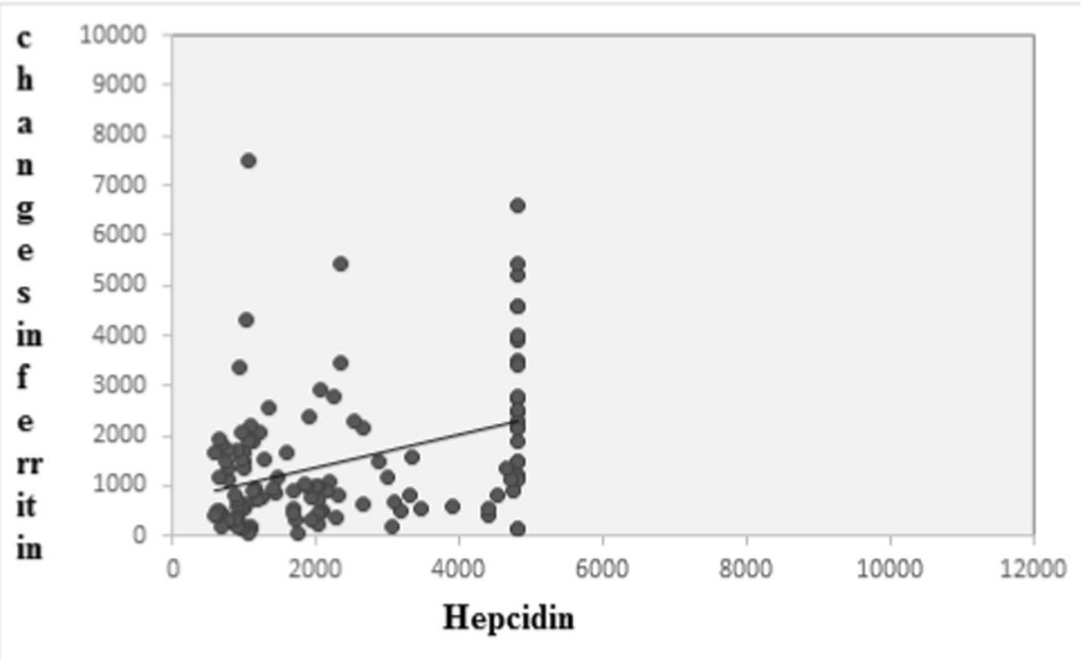


group [21], while in the present study, the difference was not statistically significant. Other studies have also suggested the measurement of urinary concentrations of hepcidin [15] and liver hepcidin mRNA levels [22] in patients with $\beta$ thalassemia and have reported no correlation with iron indices, which are in line with the results of the current study. In addition, our results show that the trend of changes in ferritin was associated with hepcidin level, which is consistent with the results of Origa et al. on urinary hepcidin levels [15].

The strength of the current study is comparing ferritin (before and after treatment with chelator) and hepcidin levels between the two groups of patients with TM and TI, which could clearly show the effect of type of thalassemia on iron status markers. Nevertheless, this study had some limitations, including the limited number of samples in the TI group and non-randomized patient selection and the lack of multiple measurements of hepcidin on several occasions. We also did not evaluate the iron levels in tissues by molecular studies or imaging methods, which could indicate tissue iron overload more accurately.

In conclusion, the results of the present study indicated that serum levels of hepcidin were high in both groups, significantly higher in the TM group, which shows the dysregulation of hepcidin in patients with $\beta$-thalassemia. Apparently, the iron excess is not absorbed by the erythropoietic system due to ineffective erythropoiesis in $\beta$-thalassemia, resulting in iron overload. In the future, measurement of hepcidin along with ferritin may provide more information about the degree of iron overload and the maldistribution of iron in thalassemia.

Acknowledgments The authors of the present study sincerely thank Miss Farhadi for technical assistance.

\section{Compliance with ethical standards}

Conflict of interest The authors declare that there is no conflict of interest.

\section{References}

1. Cao A, Galanello R (2010) Beta-thalassemia. Genet Med 12(2):6168

2. Muncie HL Jr, Campbell J (2009) Alpha and beta thalassemia. Am Fam Physician 80(4):339-344

3. Weatherall DJ (2008) Hemoglobinopathies worldwide: present and future. Curr Mol Med 8(7):592-599

4. Samavat A, Modell B (2004) Iranian national thalassemia screening program. BMJ 329(7475):1134-1137

5. Fallah MS, Samavat A, Zeinali S (2009) Iranian national program for the prevention of thalassemia and prenatal diagnosis: mandatory premarital screening and legal medical abortion. Prenat Diagn 29(13):1285-1286

6. Saffi M, Howard N (2015) Exploring the effectiveness of mandatory premarital screening and genetic counselling programmes for beta-thalassaemia in the Middle East: a scoping review. Public Health Genomics 18(4):193-203

7. Rund D, Rachmilewitz E (2005) $\beta$-Thalassemia. N Engl J Med 353(11):1135-1146

8. Ozment CP, Turi JL (2009) Iron overload following red blood cell transfusion and its impact on disease severity. Biochim Biophys Acta 1790(7):694-701

9. Ashayeri N, Sadeghi E, Sadeghi S, Eshghi P, Alavi S (2016) Efficacy of Deferasirox (Exjade $\left.{ }^{\circledR}\right)$ versus Osveral ${ }^{\circledR}$ in treatment of Iron overload in patients with Beta-thalassemia major in Iran; a non-randomized controlled trial. Iran J Blood Cancer 8(4):103-107

10. Taher AT, Porter J, Viprakasit V, Kattamis A, Chuncharunee S, Sutcharitchan P, Siritanaratkul N, Galanello R, Karakas Z, Lawniczek T, Ros J, Zhang Y, Habr D, Cappellini MD (2012) Deferasirox reduces iron overload significantly in nontransfusiondependent thalassemia: 1-year results from a prospective, randomized, double-blind, placebo-controlled study. Blood. 120(5):970977

11. Gardenghi S, Marongiu MF, Ramos P, Guy E, Breda L, Chadburn A, Liu Y, Amariglio N, Rechavi G, Rachmilewitz EA, Breuer W, Cabantchik ZI, Wrighting DM, Andrews NC, de Sousa M, Giardina PJ, Grady RW, Rivella S (2007) Ineffective erythropoiesis in betathalassemia is characterized by increased iron absorption mediated by down-regulation of hepcidin and up-regulation of ferroportin. Blood. 109(11):5027-5035

12. Nemeth E, Ganz T (2006) Regulation of iron metabolism by hepcidin. Annu Rev Nutr 26:323-342

13. De Franceschi L, Daraio F, Filippini A, Carturan S, Muchitsch EM, Roetto A et al (2006) Liver expression of hepcidin and other iron genes in two mouse models of beta-thalassemia. Haematologica. 91(10):1336-1342

14. Kaddah AM, Abdel-Salam A, Farhan MS, Ragab R (2017) Serum hepcidin as a diagnostic marker of severe iron overload in betathalassemia major. Indian J Pediatr 84(10):745-750

15. Origa R, Galanello R, Ganz T, Giagu N, Maccioni L, Faa G, Nemeth E (2007) Liver iron concentrations and urinary hepcidin in beta-thalassemia. Haematologica. 92(5):583-588

16. Britton RS, Leicester KL, Bacon BR (2002) Iron toxicity and chelation therapy. Int J Hematol 76(3):219-228

17. Wessling-Resnick M (2010) Iron homeostasis and the inflammatory response. Annu Rev Nutr 30:105-122

18. Melchiori L, Gardenghi S, Rivella S (2010) beta-Thalassemia: HiJAKing ineffective erythropoiesis and iron overload. Adv Hematol 2010:938640

19. Ganz T, Nemeth E (2012) Hepcidin and iron homeostasis. Biochim Biophys Acta 1823(9):1434-1443

20. Tanno T, Bhanu NV, Oneal PA, Goh SH, Staker P, Lee YT, Moroney JW, Reed CH, Luban NLC, Wang RH, Eling TE, Childs R, Ganz T, Leitman SF, Fucharoen S, Miller JL (2007) High levels of GDF15 in thalassemia suppress expression of the iron regulatory protein hepcidin. Nat Med 13(9):1096-1101

21. Haghpanah S, Esmaeilzadeh M, Honar N, Hassani F, Dehbozorgian J, Rezaei N, Abdollahi M, Bardestani M, Safaei S, Karimi M (2015) Relationship between serum hepcidin and ferritin levels in patients with thalassemia major and intermedia in southern Iran. Iran Red Crescent Med J 17(7):e28343

22. Kattamis A, Papassotiriou I, Palaiologou D, Apostolakou F, Galani A, Ladis V, Sakellaropoulos N, Papanikolaou G (2006) The effects of erythropoietic activity and iron burden on hepcidin expression in patients with thalassemia major. Haematologica. 91(6):809-812

Publisher's note Springer Nature remains neutral with regard to jurisdictional claims in published maps and institutional affiliations. 